\title{
Spain in the Euro: a general equilibrium analysis
}

\author{
Javier Andrés · Samuel Hurtado • Eva Ortega • \\ Carlos Thomas
}

Received: 13 May 2009 / Accepted: 22 October 2009 / Published online: 19 February 2010

(C) The Author(s) 2010. This article is published with open access at Springerlink.com

\begin{abstract}
This paper analyzes the determinants of Spain's macroeconomic fluctuations since the inception of the euro in 1999, with a special attention to observed growth and inflation differentials with respect to the rest of the European Monetary Union (EMU). For that purpose we estimate the Banco de España DSGE model of the Spanish economy and the rest of the Eurosystem (BEMOD). We find that observed differentials are the result of a combination of asymmetric country-specific shocks (in particular, demand and productivity shocks for growth and cost-push shocks for inflation) as well as asymmetric economic structure (especially lower nominal wage and price rigidities in Spain). Finally, we find that EMU membership has had a nonnegligible effect on observed differentials.
\end{abstract}

Keywords DSGE model · Monetary union - Growth and inflation differentials . Bayesian inference

JEL Classification $\quad \mathrm{C} 11 \cdot \mathrm{C} 51 \cdot \mathrm{E} 17$

\author{
J. Andrés \\ Universidad de Valencia, Valencia, Spain \\ e-mail: Javier.Andres@uv.es \\ S. Hurtado $\cdot$ E. Ortega $\cdot$ C. Thomas $(\varangle)$ \\ Bank of Spain, Madrid, Spain \\ e-mail: carlos.thomas@bde.es \\ S. Hurtado \\ e-mail: samuel.hurtado@bde.es \\ E. Ortega \\ e-mail: eortega@bde.es
}




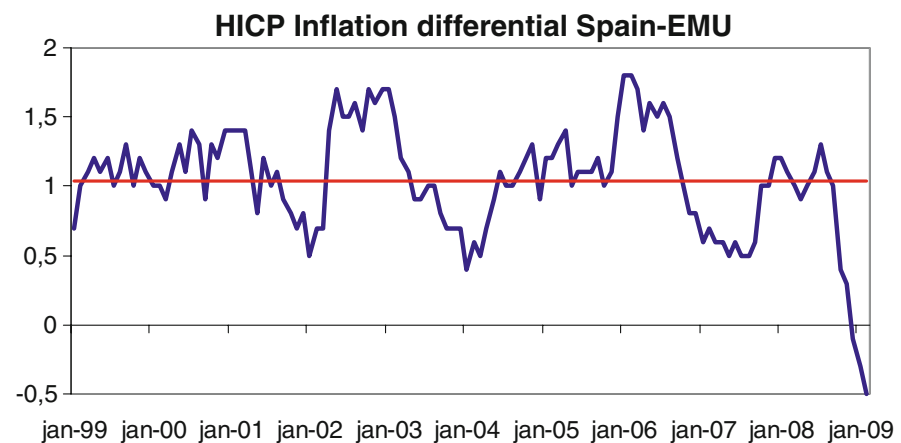

- Average inflation differential since start of EMU

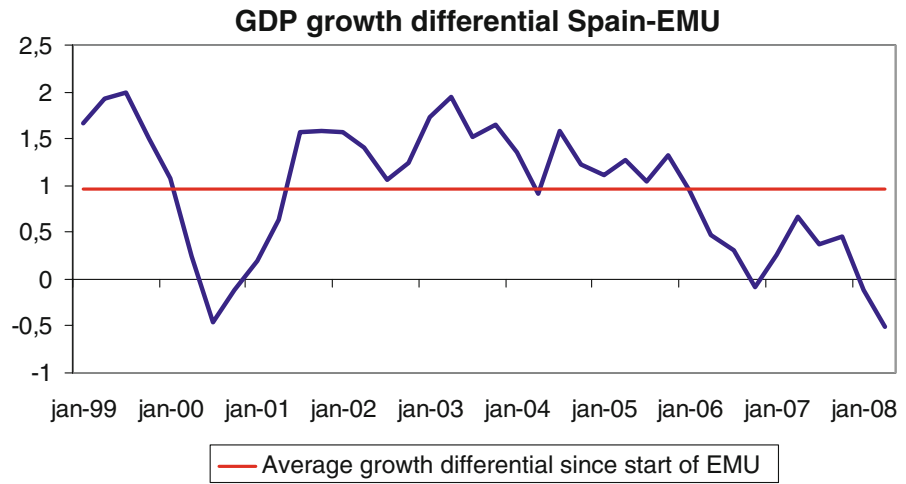

Fig. 1 Inflation and growth differentials between Spain and EMU

\section{Introduction}

The aim of this paper is to study the determinants of Spain's macroeconomic fluctuations since the inception of the euro in 1999. Despite the common monetary policy, economic developments in Spain have been closely related to those of the rest of the European Monetary Union (EMU) but certainly have differed from them at times. Indeed, during the period 1999-2007, Spanish annualized HICP inflation has been almost 1 p.p. on average above that of the EMU as a whole, while annual GDP growth has averaged 0.96 p.p. more in Spain than in the EMU (see Fig. 1). Policymakers and researchers have mentioned several possible reasons behind this distinct behavior of the Spanish economy with respect to the rest of the Eurosystem: different economic structures or institutions in several markets, most notably the labor market, different economic policies, different cyclical position, and different shocks hitting the economy.

This paper analyses the sources and implications of the differential behavior of the Spanish economy using the Banco de España DSGE model of Spain and the rest of the Eurosystem (BEMOD). DSGE models are increasingly used by central banks, both as a laboratory for simulating risk scenarios, to assess the effects of possible economic policies and as a forecasting tool. They have become popular because of their solid 
economic foundations and because the sources of fluctuations (shocks to technology, preferences, monetary and fiscal policy, etc.) have a clear structural interpretation. Central Banks using DSGE models as their main macroeconomic tool (Tovar 2008) ${ }^{1}$ unmistakably report its usefulness in that they help give a clear structure to the in-house economic discussions.

BEMOD is the model the Bank of Spain developed for policy analysis (see Andrés et al. 2006). It was the first DSGE model in the Eurosystem to incorporate two endogenous country blocks (Spain and the rest of the Euro Area) within the European Monetary Union, which in turn interacts with the rest of the world. It was also the first to include several production sectors: tradables, non-tradables and durables. The model also contains all the standard features of the latest vintage of new-Keynesian DSGE models, such as nominal rigidities and indexation of prices and wages, habit formation, investment adjustment costs and variable capital utilization. BEMOD was calibrated to reproduce the main ratios of the corresponding economies, and has been extensively used since then in scenario analysis and policy simulation exercises at the Bank of Spain (see Banco de España Annual Report 2007; López et al. 2008, or Álvarez et al. 2009, among others).

This paper revisits the model and estimates, using standard Bayesian procedures, the main parameters driving its dynamics as well as a wide variety of shocks that have hit the Spanish economy and the rest of the Eurosystem in the last decade. ${ }^{2}$ In this paper, the model has been augmented with respect to its original structure in several ways, such as adjustment costs in investment (rather than in capital) and foreign trade, Calvo-type employment smoothing functions (as in Smets and Wouters 2003) and an EMU-wide exogenous difference-stationary technology process among others. We find that our aggregate data set (consisting of 17 series) is particularly informative with respect to the Calvo parameters (which control the degree of nominal price and wage rigidities) as well as the standard deviation of shocks. Nominal wages and prices are estimated to be somewhat more flexible in Spain. Our data set is however not very informative regarding the degree of wage indexation to CPI inflation, and so the estimate of this parameter basically reflects our prior information that it is much higher in Spain than in the rest of the Eurosystem.

Once the model is estimated, we infer the series of historical shocks that have generated the observed series. It is then possible to analyze the determinants of Spain's cyclical performance in the euro regime. Our main variables of interest are the observed differentials of GDP growth and CPI inflation with respect to the rest of EMU. In order to explain these differentials, we focus on two aspects. On the one hand, asymmetries in country-specific shocks lead to asymmetric growth and inflation fluctuations. On the other hand, even in response to common shocks, asymmetries in economic structure (as represented by the structural parameters) also imply fluctuations in growth and inflation differentials.

\footnotetext{
1 The Bank of Canada, the Riksbank, the Norges Bank, the Bank of Finland or the European Central Bank were among the first ones but now the amount of central banks who have a DSGE model for the analysis of their own economy has remarkably increased.

2 Other estimations of DSGE models of the Spanish economy can be found in Aspachs-Bracons and Rabanal (2009) and Burriel et al. (2009).
} 
Our findings can be summarized as follows. First, our historical decomposition of the observed differentials by types of shocks indicate that such differentials are largely the result of asymmetric country-specific shocks. We find a particularly relevant role for demand and productivity shocks in the case of growth differentials, whereas costpush shocks are the major force behind inflation differentials. This result is further confirmed by a counter-factual simulation in which we generate differentials under the assumption that the shocks specific to Spain are the same as those specific to the rest of EMU; our simulation shows that such counter-factual differentials would have behaved rather differently from the actual ones. Interestingly, common shocks (such as oil shocks) are also an important driving force of inflation differentials, suggesting that the differences in economic structure between both regions have a relevant role in shaping such differentials. ${ }^{3}$ In order to investigate this possibility, we simulate again counter-factual differentials under the assumption that the structural parameters of the Spanish economy are the same as those estimated for the rest of EMU. We find that, while growth differentials would have been fairly similar to actual ones, inflation differentials would have been less volatile for most of the sample period. With this regard, we find a especially important role for the lower degree of nominal rigidities estimated for Spain: the fact that common shocks are transmitted faster to the prices of Spanish products (which account for the larger weight of the Spanish consumption basket) implies that such shocks have stronger effects on Spanish CPI inflation and therefore affect inflation differentials.

While Spain and the rest of the Eurosystem are hit by different shocks and also respond differently to common shocks due to structural asymmetries, both regions share a common monetary policy. As a corollary to our main results, we also analyze how Spain's membership of the EMU has shaped observed differentials. In order to investigate this issue, we set up a version of BEMOD in which both estimated parameters and historical shocks are the same as in the baseline model, but Spain retains an independent monetary policy for the peseta. We find that growth-inflation trade-offs would have been different at certain points in time in this counter-factual scenario. For instance, in the 2002-2007 period of high inflation and growth in Spain, we find that an independent Spanish monetary authority would have hypothetically implemented lower inflation and slightly lower economic growth. While interesting, these results should not be viewed as having any normative or policy implications, because the structure of the model is not designed to capture some of the most important benefits of EMU membership.

The rest of the paper is organized as follows: the Sect. 2 describes the main characteristics of the model. Section 3 reports the Bayesian estimation and assesses its properties. Section 3.2 illustrates the main transmission mechanisms of the estimated model, which exploit its multi-country and multi-sector structure. Section 4 investigates the sources of inflation and growth differentials between Spain and the rest of the Eurosystem, with a special emphasis on the role of country-specific shocks and asymmetries in the structural parameters. It also analyzes the implications of EMU membership on Spanish differentials. Finally, Sect. 5 presents some concluding remarks.

\footnotetext{
${ }^{3}$ Common shocks do not seem to be so important for growth differentials, which indicates that such shocks tend to affect growth rates rather symmetrically in both regions.
} 


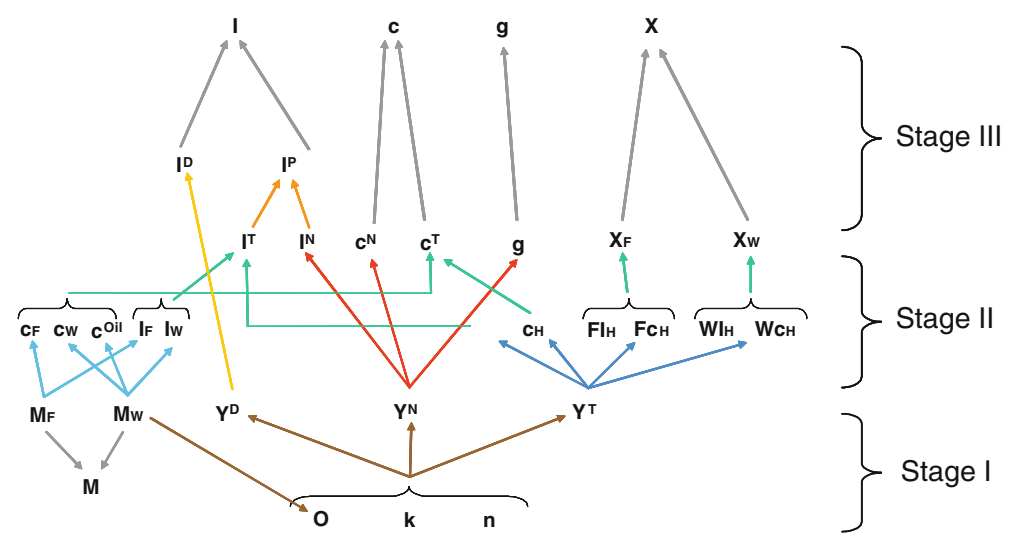

Fig. 2 Structure of production in each country

\section{The model}

There are three countries in BEMOD: Spain $(H)$, the rest of the Euro Area $(F)$ and the rest of the world $(W)$. The latter block is exogenous and consists of AR(1) processes for demand, dollar goods prices, nominal interest rates and dollar oil prices. In each of the Eurosystem economies there are four types of agents: households, firms, the domestic fiscal authority and a monetary authority common to $H$ and $F$. The representative household earns wages and rental rates of physical capital and uses his income to purchase a consumption basket, invest in productive capital and in durable goods, and buy nominal bonds (both euro- and dollar-denominated). Firms operate in three sectors: tradables, non-tradables and durables, which are produced with different technologies across sectors using labor, capital and oil. Domestic fiscal authorities collect (distortionary) taxes, consume a fraction of each country's output and issue nominal government bonds. Finally, the common monetary authority sets short-run nominal interest rates according to a Taylor rule.

The structure of production in each of the Eurosystem economies is represented by Fig. 2. In Stage I, monopolistically competitive firms in each sector use capital, labor and oil to produce differentiated goods, and set nominal prices for their products. At Stage II, competitive intermediaries aggregate both domestically produced and imported differentiated goods into baskets of intermediate goods that are then either sold domestically or exported. Finally, in Stage III, competitive final-goods aggregators combine the different baskets of intermediate goods into baskets of final consumption and investment goods, thus replicating the final demand aggregates in the national accounts.

The model contains similar departures from the competitive flexible-price model as in the latest vintage of DSGE models. These include nominal and real frictions. Nominal frictions affect goods and labour markets. There is monopolistic competition in both of them. Firms set prices in the goods markets according to a Calvo price-setting mechanisms and there is price indexation to the corresponding sector deflator. In turn, there is also a Calvo setting mechanism for wages, which are indexed to CPI. 
The real frictions included in BEMOD are investment adjustment costs, foreign trade adjustment costs, variable capital utilization and habit formation in consumption.

There is a total of 21 possible sources of fluctuations in BEMOD. Four of them occur outside the Euro Area, these are shocks to the oil price and to the rest of the world nominal interest rate, prices and demand. Three are shocks common to the whole Euro Area: to the common trend-stationary growth rate, to TFP and to the Eurosystem nominal interest rate. Finally, there are six country-specific shocks to Spain and the rest of Euro Area: to sector TFP in the tradables and non-tradables sectors, to investment, to preferences, to government expenditure and to price and wage mark-ups.

\subsection{Households' preferences}

Households maximize their welfare defined on consumption $\left(c_{t}\right)$, the stock of durables $\left(D_{t}\right)$ and leisure $\left(1-n_{t}\right)$

$$
E_{0} \sum_{t=0}^{\infty} \beta^{t} \varepsilon_{t}^{a}\left[\frac{\left(c_{t} / c_{t-1}^{\gamma}\right)^{1-\sigma}}{1-\sigma}+\frac{D_{t}^{1-\sigma_{D}}}{1-\sigma_{D}}-\frac{n_{t}^{1+\varphi}}{1+\varphi}\right]
$$

subject to the following budget constraint

$$
\begin{aligned}
& \frac{B_{t}(i)}{R_{t} \Psi\left(a_{t-1}\right)}+\frac{s_{t}^{-1} A_{t}(i)}{W R_{t} \Psi\left(a_{t-1}\right)}+P I_{t}^{P} I_{t}^{P}(i)+P_{t}^{D} I_{t}^{D}(i)+\left(1+\tau_{c}\right) \mathrm{PC}_{t} c_{t}(i)+\mathrm{PC}_{t} T_{t} \\
& \leq B_{t-1}(i)+\frac{A_{t-1}(i)}{s_{t}}+\left(\left(1-\tau_{k}\right) r_{t} k_{t-1}(i)+\sum_{S} h\left(c u_{t}^{S}(i)\right)\right) \mathrm{PC}_{t} \\
& \quad+\left(1-\tau_{w}\right) W_{t} n_{t}(i)+\int_{0}^{1} \omega_{t}(j) d j .
\end{aligned}
$$

$\beta$ is the rate of time preference, $\varepsilon_{t}^{a}$ a is preference shock, $\sigma^{-1}$ and $\sigma_{D}^{-1}$ are the intertemporal elasticity of substitution of consumption and durables services, respectively. $\varphi$ represents the (inverse of) the elasticity of labour holding the marginal utility of consumption constant, $\gamma$ captures the effect of habits in consumption. All households are Ricardian and there is no explicit role for money in the model.

Households own durables and capital, which is supplied to producing firms at the rental cost $r_{t}$, and hold their wealth in a menu of assets including domestic bonds $(B)$ and international (dollar-denominated) assets $(A) . s_{t}$ is the nominal exchange rate. There are portfolio adjustment costs, $\Psi($.$) , which are increasing in the ratio of net$ foreign asset position over value-added, $a_{t} \equiv A_{t} /\left(v a_{t} P v_{t}\right)$, and which guarantees stationarity of this ratio. ${ }^{4}$

\footnotetext{
${ }^{4}$ See e.g. Schmitt-Grohe and Uribe (2003).
} 
Final consumption goods are produced by competitive firms with a technology represented by the following CES aggregator,

$$
c_{t}=\left[\left(\omega_{C}^{N}\right)^{\frac{1}{\rho}}\left(c_{t}^{N}\right)^{\frac{\rho-1}{\rho}}+\left(\omega_{C}^{T}\right)^{\frac{1}{\rho}}\left(c_{t}^{T}\right)^{\frac{\rho-1}{\rho}}\right]^{\frac{\rho}{\rho-1}}
$$

where $\rho$ is the elasticity of substitution between traded $\left(c_{t}^{T}\right)$ and non-traded goods $\left(c_{t}^{N}\right)$. The associated price index is given by,

$$
\mathrm{PC}_{t}=\frac{\mathrm{PC}_{t}^{N} c_{t}^{N}+\mathrm{PC}_{t}^{T} c_{t}^{T}}{c_{t}}
$$

where $\mathrm{PC}^{N}$ represents the consumption price of the non-traded good and $\mathrm{PC}^{T}$ the corresponding price for the traded goods. The relative demand of non-traded versus traded goods only depends on its relative prices

$$
\frac{c_{t}^{N}}{c_{t}^{T}}=\frac{\omega_{C}^{N}}{\omega_{C}^{T}}\left(\frac{\mathrm{PC}_{t}^{N}}{\mathrm{PC}_{t}^{T}}\right)^{-\rho}
$$

A similar CES technology holds for traded consumption $c_{t}^{T}$ as a composite good home produced consumption goods, $c_{H, t}$, goods imported from the Euro Area, $c_{F, t}$, and goods imported from the rest of the world, $c_{W, t}$ as well as oil, $c_{t}^{\text {Oil }}$ :

$$
\begin{aligned}
c_{t}^{T}= & {\left[\left(\omega_{H C}\right)^{\frac{1}{\rho^{T}}}\left(c_{H, t}\right)^{\frac{\rho^{T}-1}{\rho^{T}}}+\left(\omega_{F C}\right)^{\frac{1}{\rho^{T}}}\left(c_{F, t}\right)^{\frac{\rho^{T}-1}{\rho^{T}}}+\left(\omega_{C}^{\text {Oil }}\right)^{\frac{1}{\rho^{T}}}\left(c_{t}^{\text {Oil }}\right)^{\frac{\rho^{T}-1}{\rho^{T}}}\right.} \\
& \left.+\left(\omega_{W C}\right)^{\frac{1}{\rho^{T}}}\left(c_{W, t}\right)^{\frac{\rho^{T}-1}{\rho^{T}}}\right]^{\frac{\rho^{T}}{\rho^{T}-1}}
\end{aligned}
$$

A similar structure is defined for $c_{t}^{N}, I_{t}, I_{t}^{P}, I_{t}^{T}$ and their associated price indices.

We also assume, as Erceg et al. (2000), that each household supplies a differentiated type of labour and thus enjoys some degree of monopoly power. Furthermore, households are price-setters in the labour market but only a fraction $1-\theta^{W}$ of workers reset their nominal wage each period. This generates the following log-linear wage inflation equation,

$$
\begin{aligned}
\widehat{\pi}_{t}^{W}-\psi^{W} \widehat{\pi}_{t-1}^{\mathrm{CPI}}= & \beta E_{t}\left(\widehat{\pi}_{t+1}^{W}-\psi^{W} \widehat{\pi}_{t}^{\mathrm{CPI}}\right) \\
& +\frac{\left(1-\beta \theta^{W}\right)\left(1-\theta^{W}\right)}{\theta^{W}\left(1+\varphi \varepsilon_{W}\right)}\left(\widehat{m r s_{t}}-\widehat{w}_{t}+\varepsilon_{t}^{w}\right) .
\end{aligned}
$$

where $\psi^{W}$ is the degree of indexation and $\varepsilon_{t}^{w}$ is an economy wide wage-push shock. 


\subsection{Firms' technology and price setting}

The production technology of each $j \in[0,1]$ firm in sector $S=\{N, T, D\}$ is represented by

$y_{t}^{S}(j)=\left[\varkappa_{T}^{\frac{1}{\psi^{S}}} O_{t, j}^{S}{ }^{\frac{\psi^{S}-1}{\psi^{S}}}+\left(1-\varkappa_{S}\right)^{\frac{1}{\psi^{S}}}\left[\left(\mathrm{cu}_{t, j}^{S} k_{t, j}^{S}\right)^{\alpha_{S}}\left(z_{t}^{\mathrm{EA}} z_{t} z_{t}^{S} n_{t, j}^{S}\right)^{1-\alpha_{S}}\right]^{\frac{\psi^{S}-1}{\psi^{S}}}\right]^{\frac{\psi^{S}}{\psi^{S}-1}}$

where $O_{t, j}^{S}$, is the oil input in production, ${ }^{5} \mathrm{cu}_{t, j}^{S}$ is capital utilization and $z_{t}^{\mathrm{EA}}, z_{t}$ and $z_{t}^{S}$ represent an Euro-Area-wide technology shock, a country-wide technology shock and a sector-specific technology shock, respectively.

Likewise we assume Calvo pricing with different probability of changing prices in each sector/country $\left(1-\theta^{S}\right)$. This yields the following sector specific deflator inflation equation,

$$
\widehat{\pi}_{t}^{S}-\psi \widehat{\pi}_{t-1}^{S}=\beta E_{t}\left(\widehat{\pi}_{t+1}^{S}-\psi{ }^{S} \widehat{\pi}_{t}^{S}\right)+\frac{\left(1-\beta \theta^{S}\right)\left(1-\theta^{S}\right)}{\theta^{S}}\left(\widehat{m c}_{t}^{S}+\varepsilon_{t}^{p}\right),
$$

where $\psi^{S}$ represents the degree of indexation and $\varepsilon_{t}^{p}$ is an economy wide cost-push shock.

\subsection{Monetary policy and fiscal policies}

The model is closed with the policy rules: one fiscal rule for each country and a common monetary rule. The government budget constraint is defined as:

$$
\frac{B_{t}}{R_{t}}=B_{t-1}+P_{t}^{N} g_{t}+\mathrm{PC}_{t} T_{t}-\tau^{k} \mathrm{PC}_{t} r_{t} k_{t}-\tau^{w} W_{t} n_{t}-\tau^{c} \mathrm{PC}_{t} c_{t}
$$

Fiscal policy is designed to prevent the level of debt from exploding. All $\tau^{w}, \tau^{k}$ and $\tau^{c}$ are assumed constant and we shall assume that lump-sum taxes $\left(T_{t}\right)$ respond sufficiently to deviations of the level of debt as a proportion of GDP $\left(b_{t}\right)$ from target $\bar{b}$,

$$
T_{t}=T_{0}-T_{1}\left(\frac{B_{t-1}}{P v_{t-1} v a_{t-1}}-\frac{\bar{B}}{\overline{P v} \overline{v a}}\right)
$$

Monetary policy is modeled as a Taylor rule as (in log-linear form),

$$
\begin{aligned}
\widehat{R}_{t}= & \left(1-\rho_{R}\right)\left[\rho_{\pi}\left(0.1 \widehat{\pi}_{t}^{\mathrm{CPI}}+0.9 \widehat{F \pi}_{t}^{\mathrm{CPI}}\right)+\rho_{v a}\left(0.1 \widehat{\Delta v a}_{t}+0.9 \widehat{\Delta F v a}_{t}\right)\right] \\
& +\rho_{R} \widehat{R}_{t-1}+\varepsilon_{t}^{R} .
\end{aligned}
$$

\footnotetext{
5 Following the evidence from input-output tables, we assume that oil is used in the production of tradable and non-tradable goods, but not in the production of durables.
} 
where $\widehat{\pi}_{t}^{\mathrm{CPI}}$ and $\widehat{F \pi}_{t}^{\mathrm{CPI}}$ are the home and EMU CPI inflation rates, and first differences in value added represent the output gap. $\rho_{R}$ captures the degree of interest rate smoothing and $\rho_{\pi}$ and $\rho_{y}$ the elasticity of response to deviations of inflation and output from target. The weights attached to domestic and foreign variables in the rule correspond to the relative size of the two economies; Spain represents roughly $10 \%$ of EMU GDP. $\varepsilon_{t}^{R}$ represents the unanticipated component of monetary policy.

\section{Model parameterization and assessment}

The parameterization strategy consists of keeping some parameters fixed and estimating those related to model dynamics using Bayesian techniques. The estimated parameters make a total of 60 , which include those governing (1) the dynamics of sector output prices and wages, including both Calvo and indexation coefficients, (2) adjustment dynamics of investment and employment, (3) the Taylor rule coefficients describing the systematic behavior of the common monetary policy, and (4) the stochastic processes driving all 21 model shocks, including their first order autocorrelations and standard deviations. The parameters we choose to keep fixed at their calibrated values correspond to the steady state ratios (share of non-tradables in consumption, etc., calibrated to match long-run averages in the data), the preferences (including the discount factor, inter- and intra-temporal elasticities of substitution, labor supply elasticity, habits) ${ }^{6}$ and the technology of production (factor shares and capital depreciation and utilization, calibrated to match input-output tables and longrun shares in the data).

The following Table 1 summarizes the main calibrated parameters. The rest of the calibrated values can be found in Andrés et al. (2006).

The Bayesian estimation process (carried out using Dynare) involves combining the estimation of the parameters by maximum likelihood using an observed set of data with the information obtained from prior distributions defined for those same parameters. The data set used includes quarterly observations of the 17 macroeconomic aggregates that capture the most relevant aspects of the Spanish economy and its relationship to the Eurozone, as well as the multi-country and multi-sector dimensions included in the model. These are:

- For Spain total real value added, employment in the traded and the non-traded sectors, real private consumption, real private productive investment, HICP inflation, real wages, and total exports.

- For the Eurosystem same as for Spain except exports, plus the nominal 3-month interest rate.

- For the rest of the world nominal 3-month interest rate in the US.

The set of observed variables seems to capture reasonably well the main features of the wage and price setting mechanism (see Guerron-Quintana 2008). We have explored some other combinations of series but they did not provide better estimation

\footnotetext{
6 We choose the intertemporal elasticity of consumption goods and of durables $\sigma=1$ since we need log-utility in both to guarantee balanced growth, while we calibrate the habits in consumption because the estimated value tends to become almost 1, which was inconsistent with balanced growth.
} 
Table 1 Main calibrated parameters

\begin{tabular}{lll}
\hline & Spain/EMU & Description \\
\hline$\beta$ & 0.99 & Inter-temporal discount factor \\
$\sigma^{-1},\left(\sigma^{D}\right)^{-1}$ & 1 & Inter-temporal elasticity of substitution \\
$\gamma$ & 0.85 & Habits in consumption \\
$\varphi^{-1}$ & 1 & Labor supply elasticity \\
$\rho, \rho^{T}, \rho^{N}$ & 0.5 & Intra-temporal elasticity of substitution \\
$\omega_{N}^{C}$ & $0.47 / 0.58$ & Weight of non-tradables in consumption \\
$\omega_{H}^{\mathrm{CT}}$ & $0.46 / 0.43$ & Home bias: weight of home goods in tradables consumption \\
$\omega_{F}^{\mathrm{CT}}$ & $0.33 / 0.08$ & Weight of other EMU goods in tradables consumption \\
$\delta$ & 0.021 & Depreciation rate of productive capital \\
$\delta^{D}$ & 0.005 & Depreciation rate of stock of durables \\
$\alpha^{T}$ & $0.34 / 0.15$ & Capital share in tradables \\
$\alpha^{N}$ & $0.21 / 0.22$ & Capital share in non-tradables \\
$\alpha^{D}$ & $0.14 / 0.05$ & Capital share in durables \\
\hline
\end{tabular}

properties. In particular we have tried several augmented data sets. One including imports series was not particularly successful and did not improve the estimation. The same occurs when the data set is augmented with sectoral inflation and output data; in this case the estimated values for the price setting mechanism seem very much at odds with micro and macro evidence.

All the appropriate series in our sample are transformed into per-capita terms for conformity with model variables. We take quarterly growth rates of non-stationary series (consumption, investment, value-added, sectoral employments, real wages and exports) and demean each resulting series, whereas stationary series (inflation and interest rates) are simply demeaned. The estimation period used is 1997:Q1-2007:Q4 which covers the EMU but also two years prior to the start of the common monetary policy, since in practice the Spanish monetary policy and exchange rate was already closely linked to that of its future EMU partners.

The prior distributions we have assumed follow standard practice in Bayesian estimation of similar DSGE models. In particular, we assume Inverse Gamma prior distributions for non-negative parameters (like the standard deviations of the shock processes), Beta prior distributions for parameters between 0 and 1 (like the shocks autocorrelations, the Calvo and indexation parameters and the coefficient on interest rate smoothing in the Taylor rule), and prior normal distributions for the Taylor rule coefficients on the reaction to deviations of inflation and valued added growth from target or for investment adjustment costs.

Tables 2 and 3 show the posterior modes of the main parameters of interest, together with their prior mean. ${ }^{7}$ Let us discuss first the prior means. Regarding the Calvo price

\footnotetext{
7 For the parameters referring to the rest of the Euro Area economy, the table includes the comparable estimated coefficients in the New Area Wide Model of the ECB for the Eurosystem economy as a whole, which is modelled there as a small open economy (see Christoffel et al. 2008).
} 
Table 2 Parameter estimates: structural parameters

\begin{tabular}{|c|c|c|c|c|c|c|}
\hline & $\begin{array}{l}\text { Prior } \\
\text { mean }\end{array}$ & $\begin{array}{l}\text { Post. } \\
\text { mode }\end{array}$ & & $\begin{array}{l}\text { Prior } \\
\text { mean }\end{array}$ & $\begin{array}{l}\text { Post. } \\
\text { mode }\end{array}$ & NAWM \\
\hline & \multicolumn{3}{|l|}{ Spain } & \multicolumn{3}{|c|}{ Rest of Euro Area } \\
\hline Calvo. tradables, $\theta^{T}$ & 0.75 & 0.69 & $F \theta^{T}$ & 0.75 & 0.83 & $\theta^{X}=0.77$ \\
\hline Calvo. non-tradables, $\theta^{N}$ & 0.83 & 0.90 & $F \theta^{N}$ & 0.80 & 0.93 & $\theta^{H}=0.92$ \\
\hline Calvo. wages, $\theta^{W}$ & 0.75 & 0.61 & $F \theta^{W}$ & 0.75 & 0.69 & 0.77 \\
\hline Indexation. tradables, $\psi^{T}$ & 0.30 & 0.09 & $F \psi^{T}$ & 0.30 & 0.24 & $\psi^{X}=0.49$ \\
\hline Indexation. non-tradables, $\psi^{N}$ & 0.40 & 0.27 & $F \psi^{N}$ & 0.40 & 0.35 & $\psi^{H}=0.41$ \\
\hline Indexation. wages, $\psi^{W}$ & 0.75 & 0.77 & $F \psi^{W}$ & 0.25 & 0.16 & 0.63 \\
\hline \multirow[t]{2}{*}{ Investment adjustment, $\Phi$} & 4 & 1.07 & $F \Phi$ & 4 & 3.44 & 5.17 \\
\hline & & & & Monet & policy & \\
\hline \multicolumn{3}{|c|}{ Taylor rule. inflation } & $\rho_{\pi}$ & 1.5 & 1.51 & $1.9\left(0.18 \rho_{\Delta \pi}\right)$ \\
\hline \multicolumn{3}{|c|}{ Taylor rule. output growth } & $\rho_{v a}$ & 0.5 & 0.43 & 0.15 \\
\hline \multicolumn{3}{|c|}{ Taylor rule. lagged interest rate } & $\rho_{R}$ & 0.9 & 0.83 & 0.86 \\
\hline
\end{tabular}

Table 3 Parameter estimates: shocks

\begin{tabular}{|c|c|c|c|c|c|c|c|}
\hline \multirow[t]{2}{*}{ Post. modes } & \multicolumn{2}{|l|}{ Spain } & \multicolumn{2}{|c|}{ Rest EMU } & \multicolumn{3}{|l|}{ EMU-wide } \\
\hline & $\% \mathrm{SD}$ & $\mathrm{AR}(1)$ & $\% \mathrm{SD}$ & $\mathrm{AR}(1)$ & & $\% \mathrm{SD}$ & $\operatorname{AR}(1)$ \\
\hline Preferences & 1.5 & 0.73 & 1 & 0.73 & Technology & 0.2 & - \\
\hline Gov. exp. & 1.4 & 0.79 & 1.6 & 0.81 & Trend growth & 0.2 & - \\
\hline Tech traded & 4.3 & 0.66 & 7 & 0.66 & Interest rate & 0.1 & - \\
\hline Tech non-tr & 1.7 & 0.87 & 2.1 & 0.87 & \multicolumn{3}{|c|}{ Rest of the World } \\
\hline Tech inv. & 1.9 & 0.70 & 1.6 & 0.78 & Demand & 5.1 & 0.79 \\
\hline Cost-push & 3.6 & 0.77 & 0.2 & 0.76 & Prices & 0.2 & 0.77 \\
\hline Wage markup & 9.1 & 0.74 & 7.6 & 0.62 & Oil prices & 2.6 & 0.78 \\
\hline & & & & & Interest rate & 0.14 & 0.81 \\
\hline
\end{tabular}

parameters, their priors are based on studies that employ individual price data to compute frequencies of price adjustment (Álvarez and Hernando 2006; Dhyne et al. 2006). Specifically, we consider that price stickiness in the tradable sector in Spain is similar to that in the euro area and consider a mean duration of four quarters, which implies $\theta^{T}=0.75$. For non-tradables, the evidence points to higher durations. We consider durations of five quarters for the euro area and six quarters for Spain, to allow for higher price stickiness in Spain. Studies using survey data on wage setting provide a basis for the prior means of the Calvo wage parameters and the degrees of indexation to CPI inflation (Du Caju et al. 2008; Druant et al. 2008). In particular, we consider that the average duration of a wage contract is four quarters in both areas. For wage indexation, 

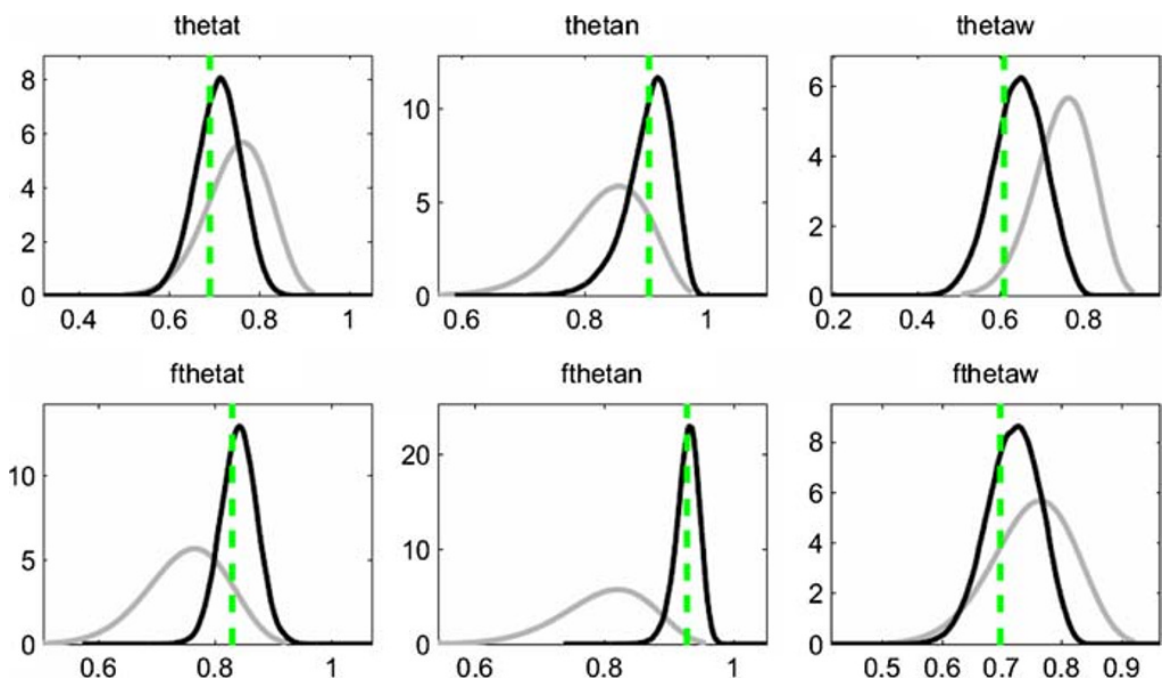

Fig. 3 Prior and posterior distributions of Calvo parameters
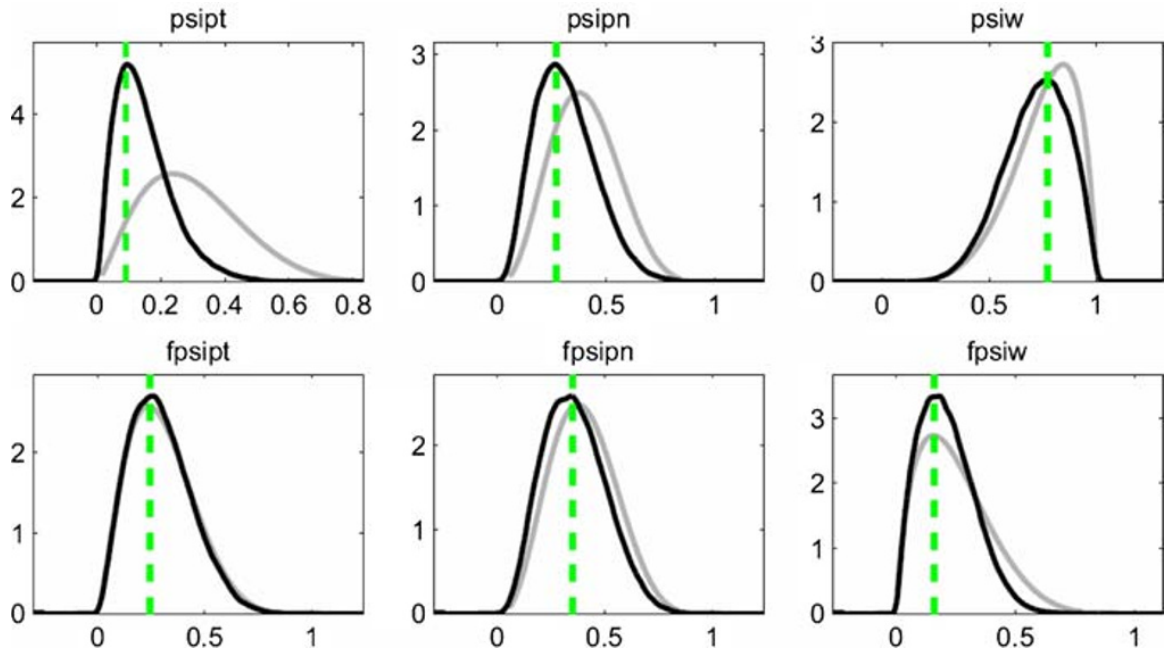

Fig. 4 Prior and posterior distributions of indexation parameters

we choose values of 0.75 and 0.25 for Spain and EMU, respectively, reflecting the more widespread use of indexation clauses in collective wage agreements in Spain.

We now discuss the posterior estimates and their relationship with the priors. In terms of price and wage dynamics, there are several aspects to point out. First, the data is particularly informative since, as can be seen in Figs. 3 and 4, it shifts the prior, quite remarkably in some cases: the black line representing the posterior distribution 

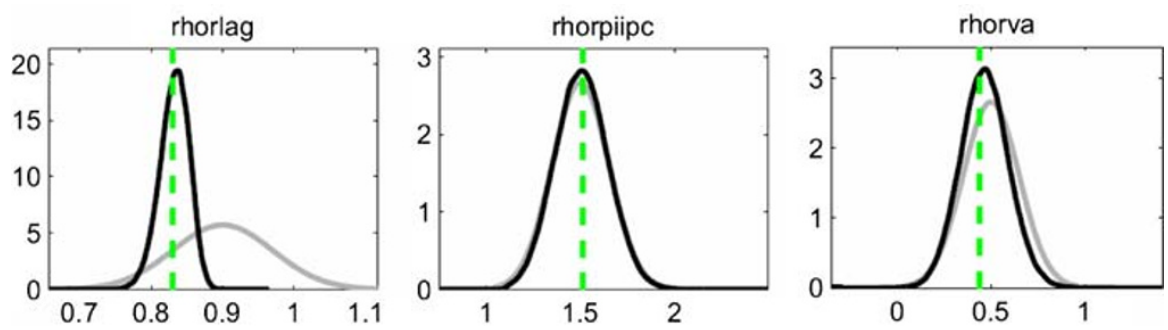

Fig. 5 Prior and posterior distributions of Taylor rule coefficients

estimated ${ }^{8}$ for each Calvo ("theta") parameter departs noticeably from its assumed prior distribution, in grey (the green vertical line indicates the posterior mode value). In the case of the indexation parameters, " $p s i$ ", the information content of the aggregate data is less clear.

Second, the estimated degree of nominal price and wage stickiness, as measured by the Calvo parameter, is found to be higher in the rest of the Eurozone than in Spain; the posterior modes obtained for the Euro Area are similar to those estimated in the NAWM, although that model does not separate between tradables and non-tradables but rather between home consumed and exported. Third, in both economies prices of non-tradables are found stickier than those of tradables, consistently with estimations elsewhere (see e.g. Rabanal 2009). Fourth, the degree of price indexation is found to be small in both countries, smaller than the micro-evidence used to build the priors and than the estimates in the NAWM. ${ }^{9}$ Fifth, the posterior distributions of both wage indexation parameters are largely coincident with their respective prior distribution (especially for Spain), suggesting the our aggregate data set does not contain much information regarding these parameters.

The monetary policy rule estimated shows substantial interest rate smoothing and point estimates that are quite close to the canonical $(1.5,0.5)$ Taylor rule. This higher response to inflation than to output is consistent with the inflation objective of the European Central Bank. The posterior estimates are quite close to their prior mean, except the one governing the degree of interest rate smoothing, which is found very close to the one estimated in the NAWM. The comparison with the NAWM estimates is more difficult for the other Taylor rule coefficients, since in that model the reaction to inflation is specified differently, both in levels and in growth rates. Although the posterior distributions of both $\rho_{\pi}$ and $\rho_{\pi}$ resemble very much their respective priors (see Fig. 5) we consider that the data is sufficiently informative about the interest rate rule, since the estimated values are relatively robust to the choice of alternative priors.

Regarding the estimated processes for the shocks of the model, a few things are worth noting. First, the larger shocks are those to the wage setting mechanism; and they are found more volatile and more persistent in Spain than in the rest of the Euro Area.

\footnotetext{
8 The posterior distributions displayed here have been obtained with 2.5 million replications of the Metropolis-Hastings algorithm.

9 Adolfson et al. (2005) obtain a similar result of low indexation in prices, consistent other estimates that also obtain strongly forward looking Phillips curves.
} 
Second, technology shocks in the traded sector are also estimated to be of relevant size, especially in the rest of the Eurozone, while they are found equally persistent in both economies. Third, shocks to world demand are also found to be very big. The next more volatile are shocks to the price setting mechanism, cost-push shocks, in Spain but not in the rest of EMU, followed by oil price shocks. Comparing the shape of the priors and posteriors we find that the data is also very informative for the estimation of the shocks processes.

We have checked the robustness of the parameter estimates by re-estimating the model excluding one of the 17 series in the data set at a time. ${ }^{10}$ With very few exceptions the posterior mode of each parameter lies really close to the full data set case and most of the modes lie within the posterior distribution of the full data set estimation.

\subsection{Assessing the model fit}

Before investigating what the model implications are for understanding the similarities and divergences between the Spanish economy and the rest of the Eurosystem we need to assess the model's overall goodness of fit. One first test is to compare the evolution of the series used in the estimation process to that predicted by the model for the same variables. Figure 6 makes such a comparison of observed data and model predictions for several of the series included in the estimation data set: value added, private consumption and investment quarterly growth rates, inflation in Spain and the Euro Area, and the nominal quarterly Eurozone and US interest rates, always in terms of deviations with respect to sample average. These results are representative of the fit that is observed in the rest of the series: despite the discrepancies observed for some periods and variables, the in-sample fit seems remarkably good. We feel comfortable interpreting model predictions as closely representing the Spanish economy within the EMU.

Using farther ahead in-sample forecasts from the model, as shown in Fig. 7, we see additional proof that the model fit is, given all its constraints, somewhat reasonable. In particular, the eight-periods-ahead projections presented in this figure show some signs of foresight from the model, though it is perhaps displaying an over-tendency to return to its steady state, especially in some variables, such as EMU growth and the nominal interest rate.

Another useful measure of fit is the comparison of sample and model moments for the observed variables. Calculations not reported here show substantial differences between the autocovariance function of the observed variables in the data and the corresponding theoretical moments in the estimated model. In particular, the model generates substantially more volatility in the observed variables than in the data, with the by-product that autocovariances and cross-covariances at different leads and lags also tend to be off target. This result contrasts with the reasonably good fit of the observed historical paths in Fig. 6. We attribute this discrepancy to the short sample period used in the estimation (44 observations), which makes the comparison between

\footnotetext{
10 We do not show the summary plots of this exercise because of space restrictions, but they are available from the authors upon request.
} 

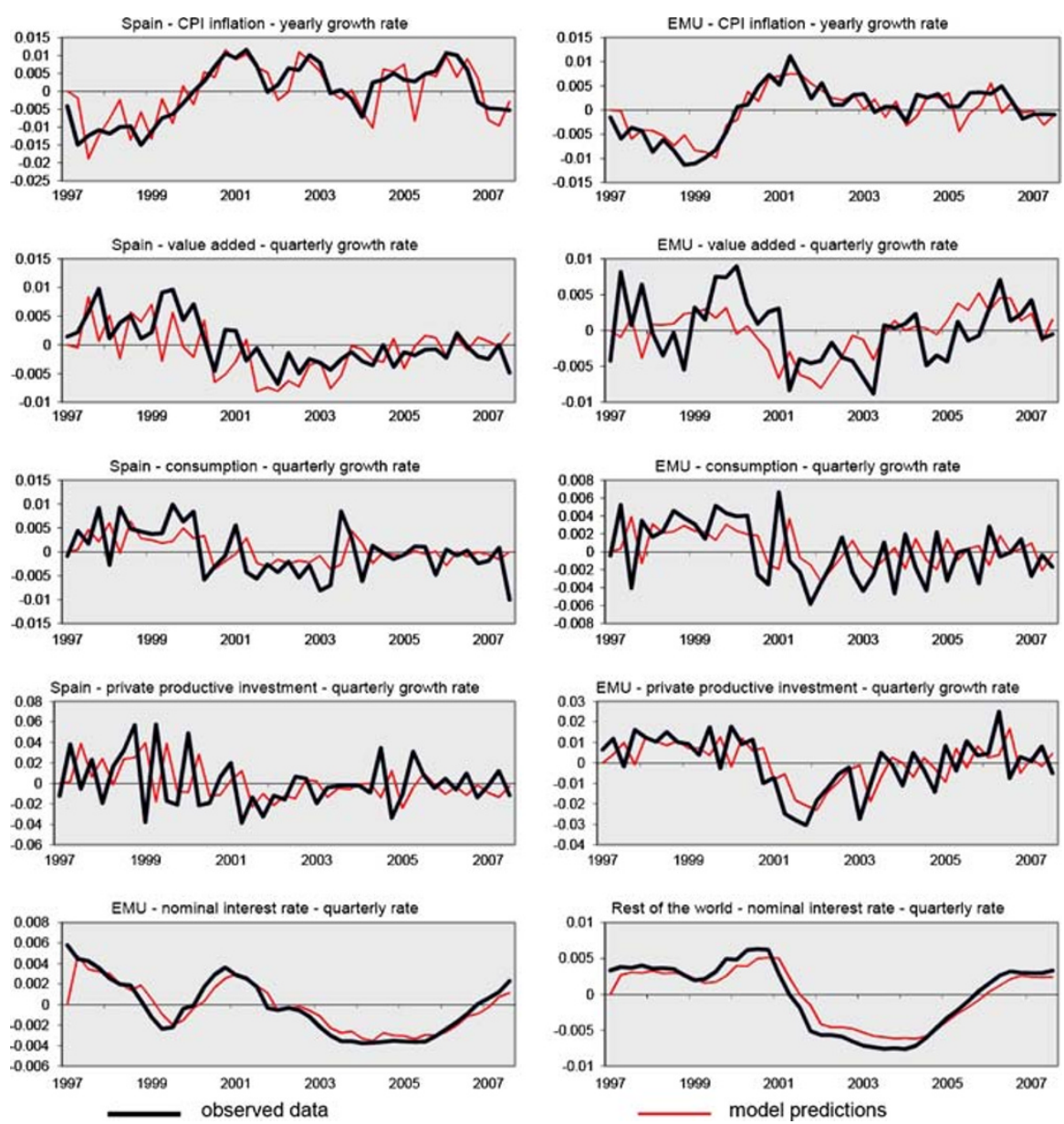

Fig. 6 Data and one-period-ahead forecast

the theoretical model moments (based on the assumption of iid shocks) and the sample moments problematic. ${ }^{11}$

\footnotetext{
11 It should be noted however that the model captures the main qualitative features of the data reasonably well. Thus, the model correctly predicts higher inflation volatility in Spain than in the rest of the Euro Area, with posterior mean standard deviations twice as big in Spain, just as in the data although both are significantly higher than the ones found in the actual data. Similarly, the model succeeds in predicting similar output volatility in Spain and EMU, although again the standard deviations are much bigger than in the data. This higher variability of the fitted series causes lower contemporaneous correlations than the observed ones. For instance, in the data the contemporaneous correlation between Spain and the Eurozone is 0.56 for value added and 0.90 for inflation. The model correctly predicts that value added fluctuations are less synchronized in EMU than in the case of inflation, but obtains lower contemporaneous correlations, of 0.35 and 0.43 respectively.
} 


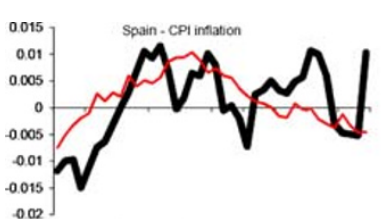

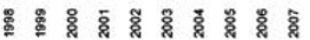

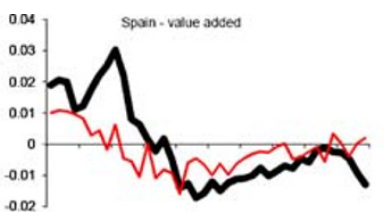

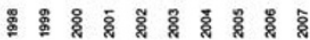

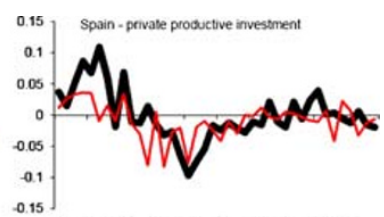

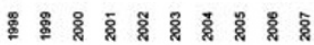

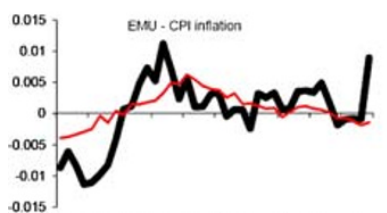

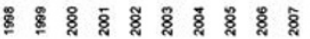

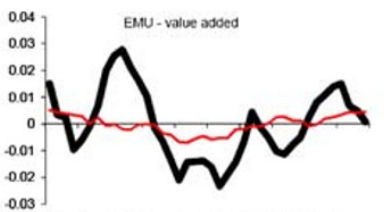

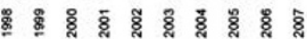

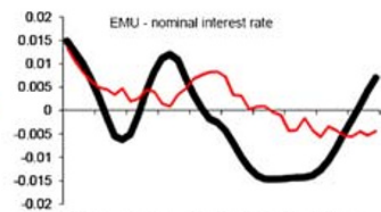

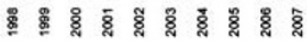

data

forecast for $t$ made at $t-8$

Fig. 7 Data and eight-periods-ahead forecast

\subsection{Model properties}

Two additional model properties are useful to assess the reliability of the model to account for the recent historical developments of the Spanish economy within the EMU: the decomposition of how much of the model series variability is due to the various shocks, by means of the forecast error variance decomposition, and the implied transmission mechanisms for the various shocks, as showed by the impulse response functions.

Starting with the forecast error variance decomposition of the main variables in the model, we have grouped the 21 shocks of the model into nine categories:

1. Rest of the world shocks to world demand, world prices, oil price and world interest rate.

2. Common shocks to the exogenous trend growth and TFP processes, which are common to Spain and the rest of EMU

3. Interest rate shocks shocks to the euro nominal interest rate

4. EMU-Prices shocks to rest of EMU markups in prices and wages (or "cost-push" shocks).

5. EMU-Productivity shocks to rest of EMU TFP in the tradables and non-tradables sectors and investment-specific technology shocks.

6. EMU-Demand shocks to rest of EMU government spending and to household preferences.

7. Spain-Prices shocks to Spanish markups in prices and wages (or "cost-push" shocks).

8. Spain-Productivity shocks to Spanish TFP in the tradables and non-tradables sectors and investment-specific technology shocks.

9. Spain-Demand shocks to government spending and household preferences in Spain.

Figure 8 decomposes the forecast error variance at various horizons: 1, 4, 8 quarters and in the very long-run. Again the estimated contribution of each shock to the more 


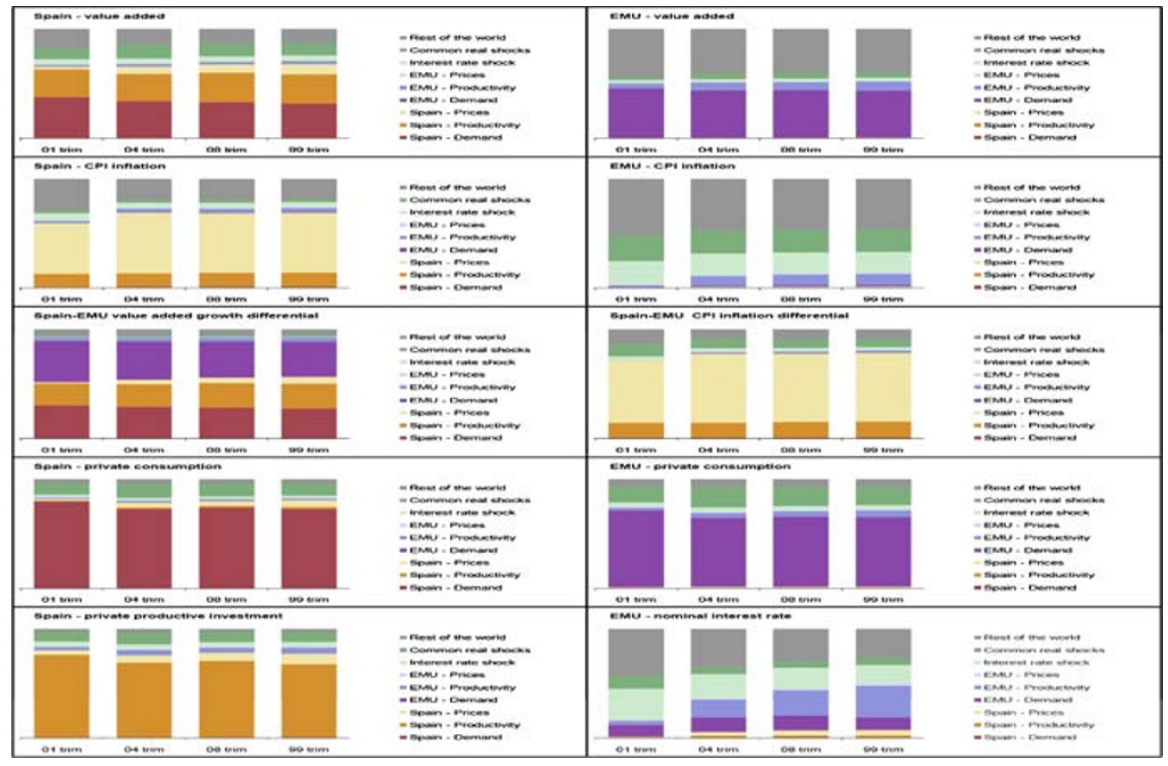

Fig. 8 Variance decompositions in the estimated model

relevant variables looks very reasonable. Spanish value added forecast error variance is mainly explained by domestic demand and productivity, while shocks common to the whole Euro Area matter as well. That of Spanish inflation depends mostly on national price and wages shocks and, to a lesser extent, on shocks coming from the rest of the world - mainly oil price shocks. The results for the Eurozone are also satisfactory: the forecast error variance of its value added depends mostly on European and rest-of-the-world demand shocks, while that of inflation depends mainly on common productivity and interest rate shocks, oil price shocks, and exchange rate shocks.

The forecast error variance of the value added growth differential between Spain and the Eurozone is, then, mainly due to both areas specific demand and supply shocks, although demand shocks play a higher role. Idiosyncratic shocks to the Spanish economy seem to have a somewhat higher weight. Common and rest of the world shocks affect but to a much lesser extent. The CPI inflation differential, in turn, depends mostly on the specific shocks that drive Spanish inflation (cost push and wage push shocks).

As expected, the main contributor to private consumption forecast error variance in both economies is the domestic demand shock, and to an even larger extent in the case of Spain. Private productive investment fluctuations are, on the contrary, mainly driven by domestic productivity shocks, while cost-push shocks and common real and monetary shocks play a significant but much lower role. The role of the common shocks is found smaller in Spain than in the rest of the EMU. Finally, it is worth noting that the forecast error variance of nominal interest rates is explained to a higher extent by the variables to which the Eurozone common monetary authority reacts through its Taylor rule-thus the importance of the shocks that drive the variance of Eurozone inflation 

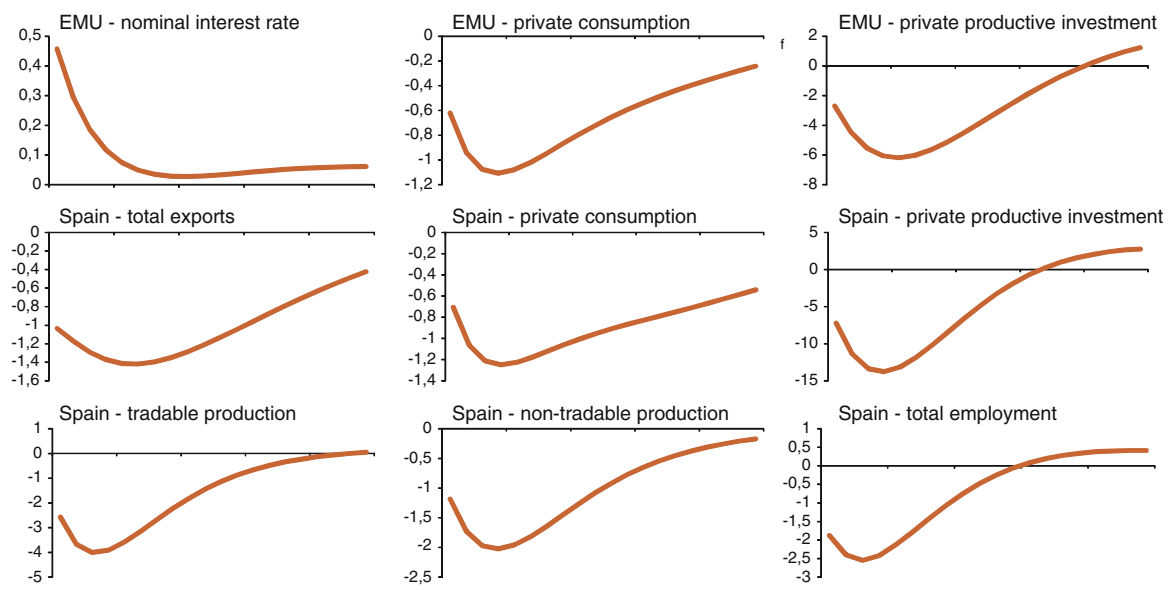

Fig. 9 Impulse-responses to a positive nominal interest rate shock

and output: oil price and world interest rates, plus European and world demand - than to intrinsic interest rate shocks.

With respect to the impulse response functions, we will present only the effects of an interest rate shock, and those of a productivity shock in the Spanish tradable goods sector. They illustrate well the multi-country and multi-sector features of the model within a monetary union. Figure 9 displays the economy's reaction to a $1 \%$ shock to the nominal common interest rate. The increase in nominal interest rate depresses private consumption and investment both in Spain and the rest of EMU. Since EMU is Spain's main trading partner, total Spanish exports fall accordingly. As a result, production in the tradables sector drops more sharply than in the non-tradables sector. The fall in production and the stickiness of nominal wages (not shown in the figure) produce a substantial fall in Spanish employment, with a maximum drop of about $2.5 \%$.

Figure 10 displays the responses to a $1 \%$ shock to productivity in Spain's tradables sector. The improvement in productivity leads to a fall in tradables producer price inflation. Spanish tradables become cheaper vis-à-vis home non-tradables and tradables from the rest of EMU and the rest of the World. As a result, tradables production increases. The latter outweighs the drop in non-tradables production (not shown in the figure), such that total value-added in Spain increases. Cheaper tradables in Spain lead to lower consumer price inflation in Spain and, to a much lesser extent, in the rest of EMU. Since the latter is the main argument in the ECB monetary policy rule, nominal interest rates fall by a tiny amount. The resulting increase in domestic demand in Spain (not shown) is not large enough to compensate for the fact that firms now need less labor to produce the same output. As a consequence, employment in the tradables industry falls, with the resulting negative effects on total employment.

\section{The sources of growth and inflation differentials}

Now we turn to analyzing the sources of the observed growth and inflation differentials between the Spanish economy and the rest of the Eurosystem. Here we focus on 


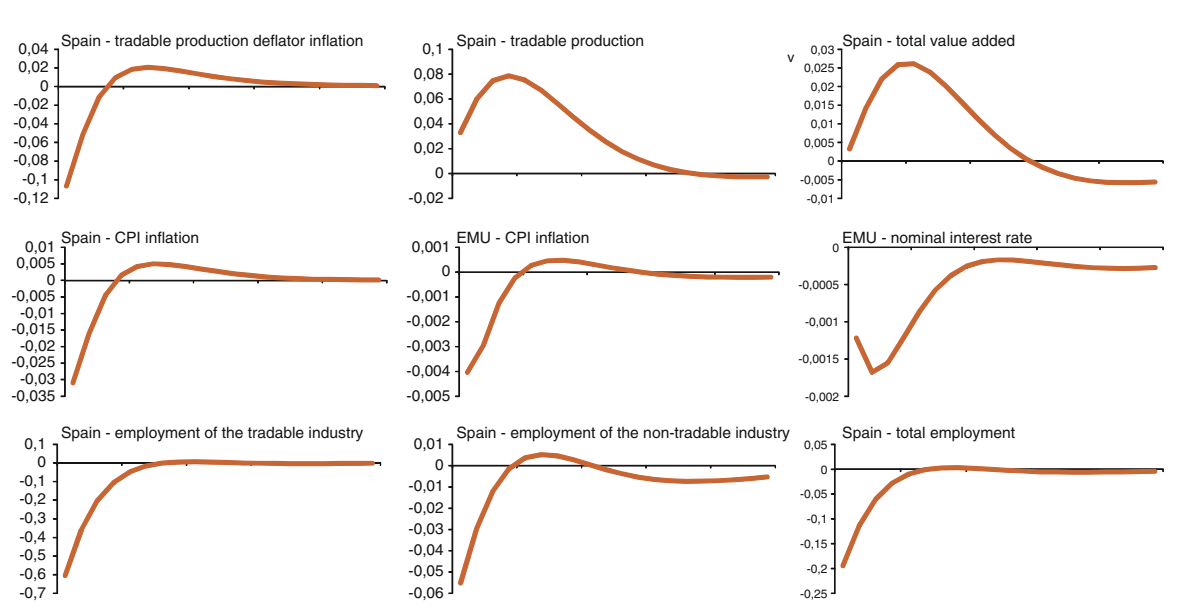

Fig. 10 Impulse-responses to a positive productivity shock in Spain's tradables sector

three potential explanations: differences in economic structure (as represented by the structural parameters that are being estimated), asymmetries in the country-specific historical shocks, and Spain's membership of the Euro Area.

Once the model is estimated, it is possible to combine the observed series and the state-space representation of the estimated model so as to infer the series of historical shocks that would have produced exactly the observed series. ${ }^{12}$ By simulating the path of the endogenous variables conditional on each series of historical shocks, we can then calculate the contribution of each particular type of shock to the observed series.

Figure 11 displays the contribution of different groups of shocks to observed yearon-year per capita GDP growth in Spain and the rest of EMU, as well as to the resulting growth differential. ${ }^{13}$ The solid lines represents the observed series, in annual averages of quarterly observations. It is important to note that, since all our observable series have been demeaned prior to estimation, the structural shocks of the model explain only the deviations of each variable with respect to its sample average. Hence, the contributions of the diverse type of shocks add up to the observed differential series minus its sample average.

As the lower panel shows, growth differentials all throughout the sample period are largely the result of shocks specific to Spain and shocks specific to the rest of EMU. For instance, the significant reduction in Spain's relative growth in 2000 was mainly due to the positive effect of EMU-specific demand shocks on rest-of-EMU growth and the negative effect of Spain-specific productivity shocks on Spanish growth. Similarly, the fall in growth differentials in 2006 can be largely explained by adverse Spain-specific price (cost-push) shocks as well as beneficial EMU-specific productivity and demand shocks. Note finally that, although shocks from the rest of the World have had

\footnotetext{
12 The estimated historical shocks are available upon request from the authors.

13 Part of the evolution of the series at the start of the sample period is determined by the initial conditions infered for the state variables (labelled "carry-over" in Figs. 11, 12). It can be seen however that this effect disappears quickly.
} 


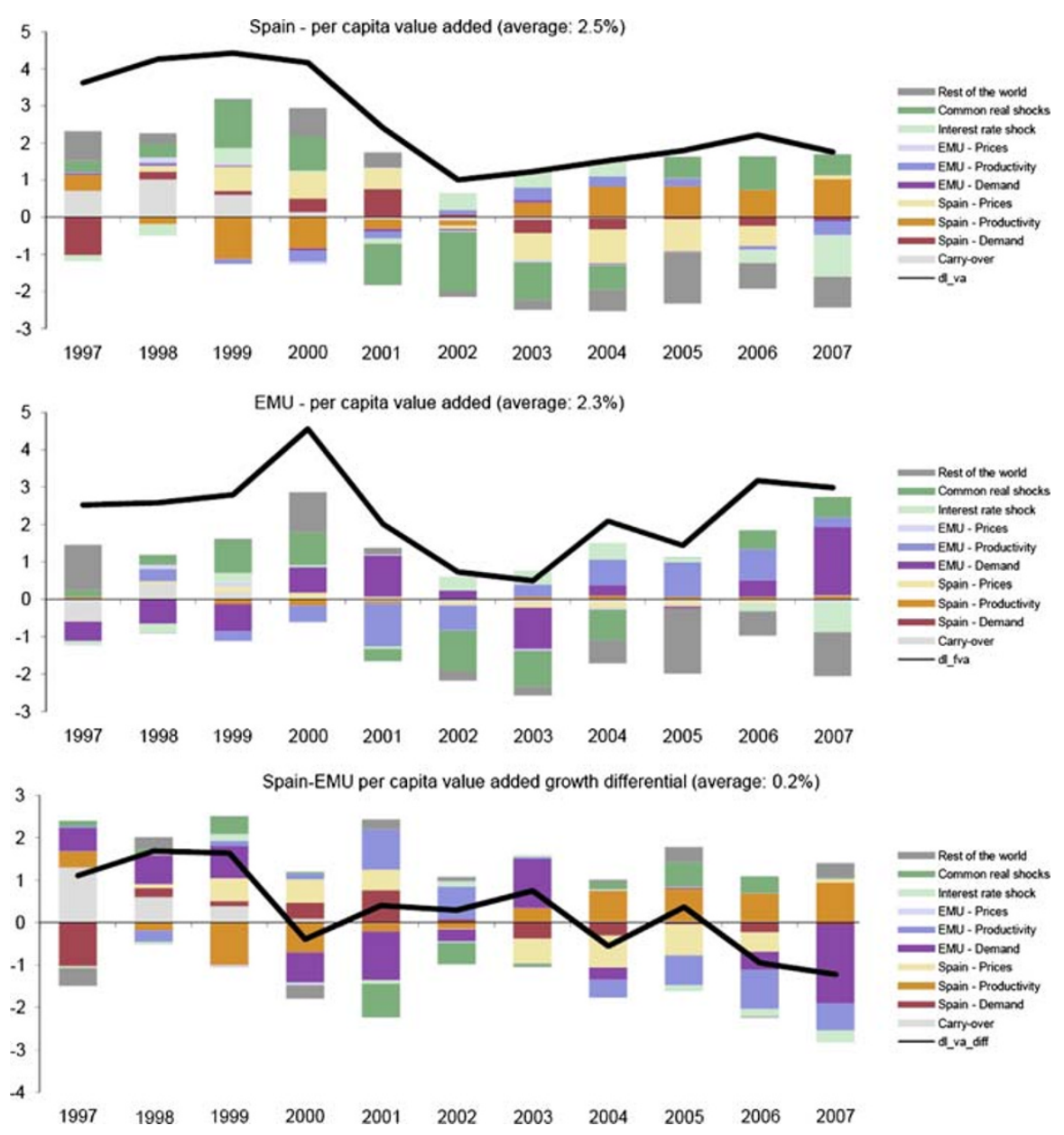

Fig. 11 Contribution of each group of shocks to GDP growth differentials

an important effect on each region's GDP growth at certain historical dates, the fact that their effects are fairly symmetric implies that they have not made an important contribution to growth differentials.

Figure 12 shows the contribution of each group of shocks to observed CPI inflation rates and their differential over our sample period. The latter series has remained fairly stable since 1999. The model attributes the stability in Spanish inflation to the fact that the effects of Spain-specific cost-push shocks has tended to be offset by the effects of Spain-specific productivity shocks. This is especially true in 1999-2001, where the effects of both types of shocks basically canceled each other out. This pattern translates to the decomposition of inflation differentials (lower panel), where Spainspecific shocks are clearly dominant. On the other hand, demand shocks have been largely irrelevant for inflation in both regions; this probably reflects the high degree of nominal rigidities estimated for both areas and hence the relatively low sensitivity 

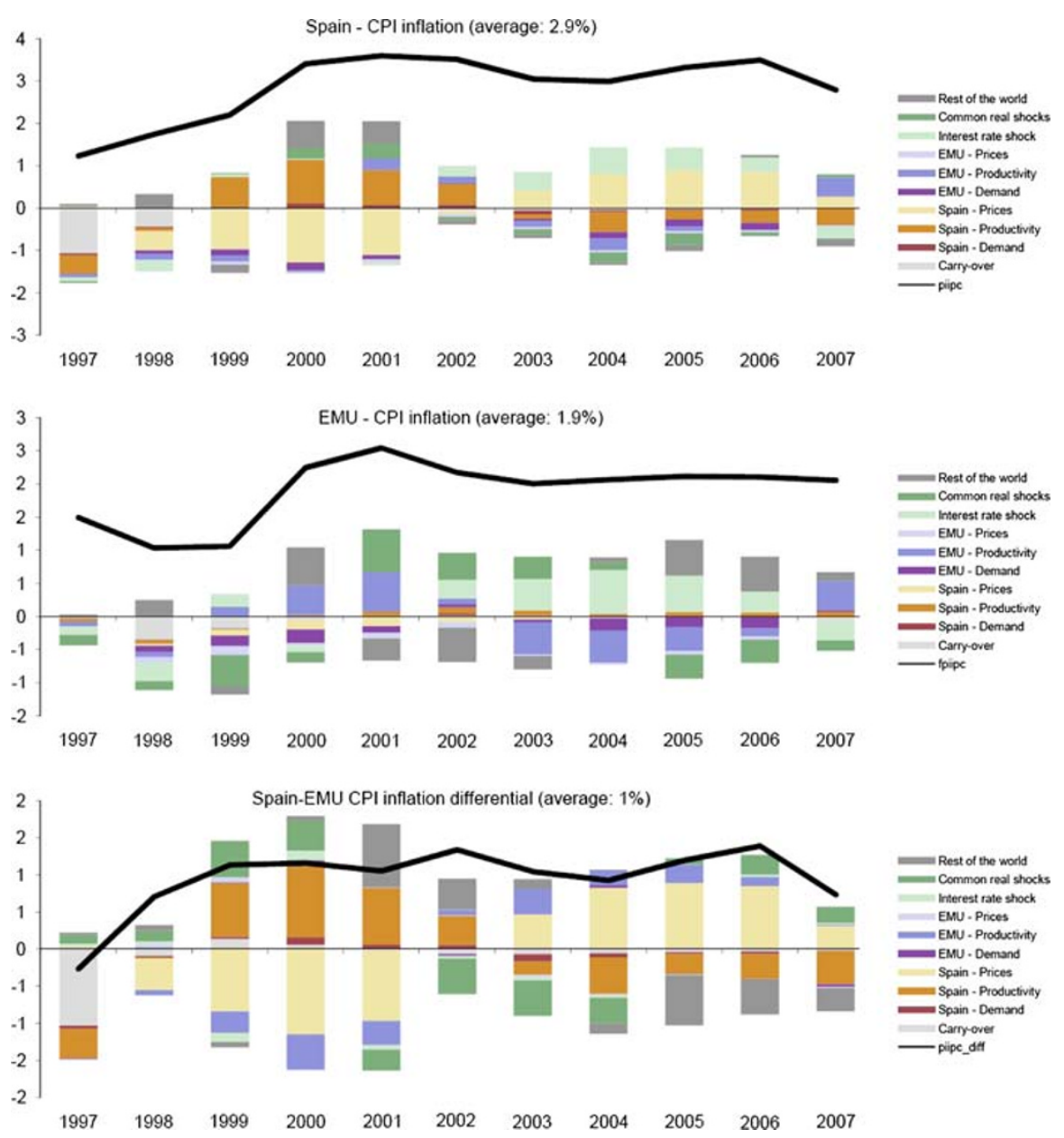

Fig. 12 Contribution of each group of shocks to CPI inflation differentials

of prices to aggregate demand fluctuations. Finally, unlike in the case of GDP growth differentials, shocks from the rest of the World do seem to have played an important role for inflation differentials, the reason being that their effects on country-specific inflation rates are rather asymmetric. A clear example is the year 2001, where rest-ofthe-World shocks had a positive effect on Spanish inflation but a negative effect on rest-of-EMU inflation. The estimated historical shocks (not shown here for brevity, but available upon request) indicate large rises in the real price of crude oil in that year, consistently with the evidence, as well as other rest-of-the-World shocks that counteracted the oil shocks (hence the negative contribution to EMU inflation). Given Spain's stronger dependence on oil both in the consumption basket of households and in production processes, such oil shocks had larger effects on Spain's CPI inflation relative to EMU, thus leading to higher inflation differentials. Similarly, the lower Calvo parameters estimated for Spain imply that shocks from the rest of the World 
transmit faster to the price of Spanish products. Since the latter account for most of the weight in the Spanish CPI (and a very small weight in the rest-of-EMU CPI), we have that such shocks produce stronger responses in Spanish CPI inflation.

\subsection{The role of asymmetries in shocks and structure: counter-factual exercises}

The contribution of each group of shocks to growth and inflation differentials are the result not only of different shocks hitting the Spanish and rest-of-EMU economies, but also of different economic structures shaping the transmission of a given shock in both regions. In fact, both elements interact in a way that makes it impossible to decompose the actual differentials as the sum of the effect of shocks plus the effect of economic structure.

It is however possible to identify the contribution of each of these two elements vis-à-vis the baseline model, by doing the following counterfactual exercises. Let $\left(P, P^{*}\right)$ denote the parameter estimates specific to Spain and the rest of EMU, respectively. Let also $\left(S, S^{*}\right)$ denote the historical shocks specific to Spain and the rest of EMU, respectively. Let $y\left(p, p^{*} ; s, s^{*}\right)$ be the path of Spain's observable variables generated by the state-space representation of the model for certain parameter values $\left(p, p^{*}\right)$ and certain exogenous shocks $\left(s, s^{*}\right)$, and let $y^{*}\left(p, p^{*} ; s, s^{*}\right)$ be the corresponding function for the rest-of-EMU observables. Evaluating $y$ and $y^{*}$ at the estimated parameters and historical shocks and taking differences, we obtain exactly the observed differentials, which we denote by

$$
y_{\mathrm{diff}} \equiv y\left(P, P^{*} ; S, S^{*}\right)-y^{*}\left(P, P^{*} ; S, S^{*}\right) .
$$

\subsubsection{The effect of shocks asymmetries}

We now define

$$
y_{\text {diff }}^{S} \equiv y\left(P, P^{*} ; S^{*}, S^{*}\right)-y^{*}\left(P, P^{*} ; S^{*}, S^{*}\right)
$$

which is the set of differentials that would have been observed if the shocks specific to the Spanish economy had been exactly the same as the shocks specific to the rest of EMU. ${ }^{14}$ By comparing these counter-factual differentials to the actual differentials $\left(y_{\text {diff }}\right)$, we can isolate how the latter have been affected by the occurrence of country-specific shocks.

Figure 13 compares actual (solid line) and counter-factual (dotted line) differentials in GDP growth and CPI inflation, both in deviations from their actual sample average. As indicated by the upper panel, in the counterfactual scenario with symmetric country-specific shocks the growth differential would have been lower in 2001 and the first

\footnotetext{
14 By "same shocks" we mean that the series of the exogenous AR(1) processes (not just the iid shocks to such processes) are the same in both regions. We do so because what matters for equilibrium dynamics is the value of the exogenous variables themselves. Indeed, given that we have estimated different autocorrelation coefficients for the comparable AR(1) processes in both region, equalizing the iid shocks would actually imply different paths for the exogenous variables.
} 

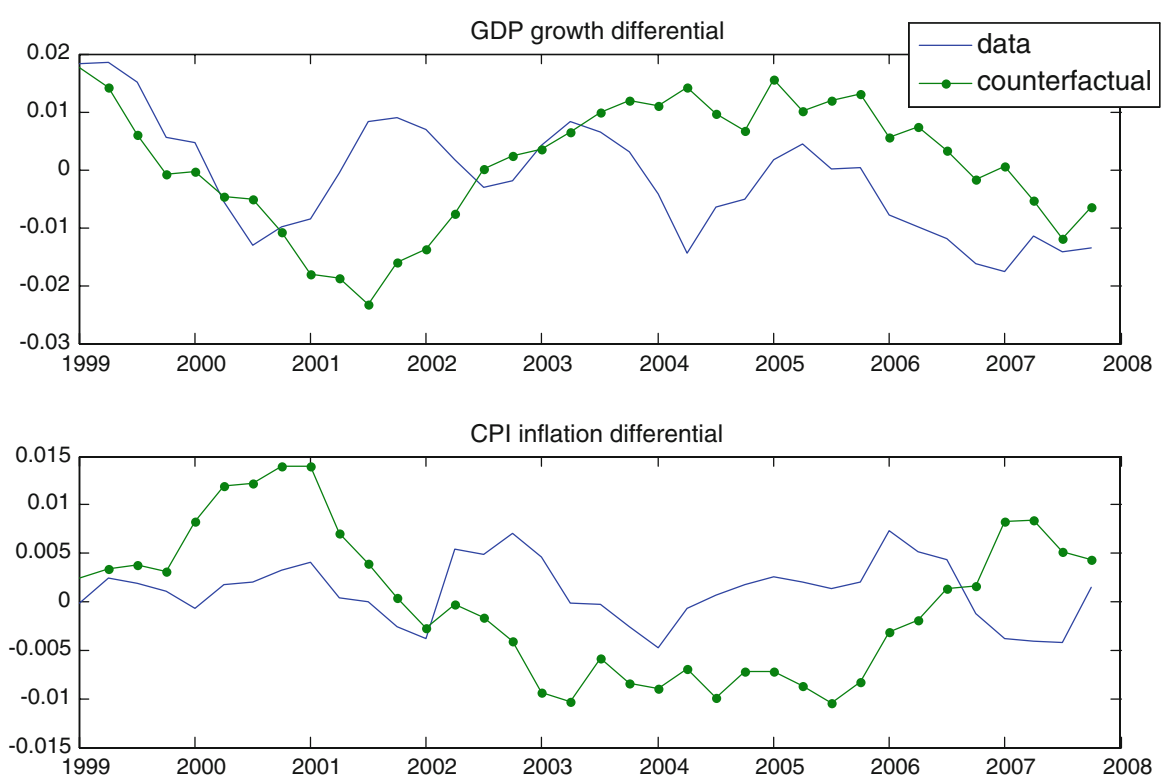

Fig. 13 The effect of shock asymmetries on differentials

half of 2002, and higher from them onwards. Figure 11 above gives some guidance for interpreting these results. According to that figure, in 2001 the adverse effects of negative EMU-specific productivity shocks on EMU growth was far larger than the adverse effects of Spain-specific productivity shocks on Spanish growth. Therefore, if Spain-specific productivity shocks had had the same magnitude as EMU-specific productivity shocks, relative growth in Spain would have been weaker in 2001, and this situation would have persisted in 2002. Similar interpretations can be made for explaining the higher counterfactual differentials from 2003 onwards.

Regarding inflation differentials, the lower panel of Fig. 13 shows that they would have been higher up until 2002:Q1, lower from 2002:Q2 to 2006:Q3, and again higher in the last part of the sample. The decomposition of observed inflation differentials in Fig. 12 is helpful for interpreting these results. According to that figure, whereas EMUspecific cost-push (price) shocks had negligible effects on EMU inflation in 20032007, Spain-specific cost-push shocks had large positive effects on Spanish inflation in the same period, a pattern that translated to inflation differentials. As a result, should Spanish cost-push shocks have been the same as EMU cost-push shocks, inflation differentials would have been substantially lower. Similar interpretations can be made regarding the counter-factual inflation differentials in the rest of the sample period.

\subsubsection{The effect of structural asymmetries}

Let us now define

$$
y_{\text {diff }}^{P} \equiv y\left(P^{*}, P^{*} ; S, S^{*}\right)-y^{*}\left(P^{*}, P^{*} ; S, S^{*}\right)
$$



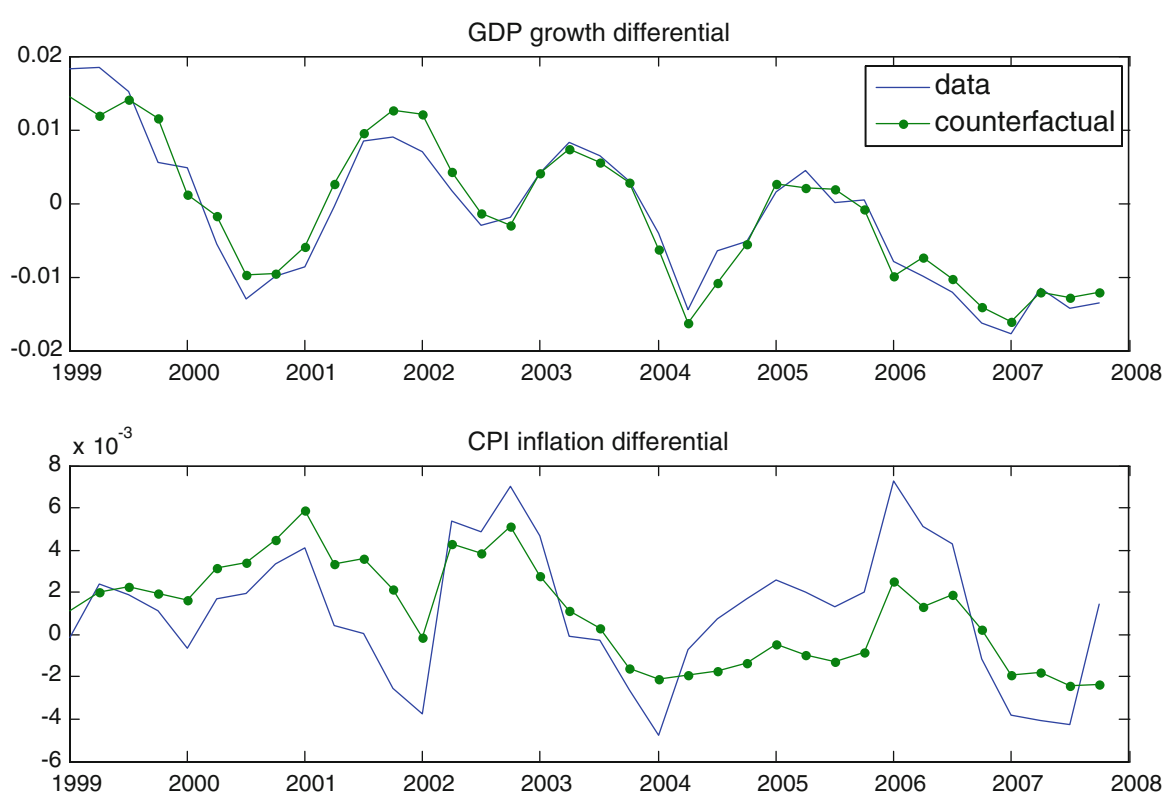

Fig. 14 The effect of structural asymmetries on differentials

that is, the set of differentials that would have been observed if the structural parameters specific to the Spanish economy had been exactly the same as the parameters estimated for the rest of EMU. We can then compare these counter-factual differentials to the actual ones in order to isolate the extent to which the latter are the result of differences in economic structure between Spain and the rest of EMU. Such structural differences include:

1. Average frequency of adjustment of nominal prices and wages (Calvo parameters),

2. Degree of backward-looking indexation of nominal prices (to producer price inflation) and nominal wages (to consumer price inflation), and

3. Investment adjustment costs.

Figure 14 compares observed actual differentials ( $y_{\text {diff }}$, solid line) and counterfactual differentials ( $y_{\text {diff }}^{P}$, dotted line) again for year-on-year GDP growth and CPI inflation, net of the sample average of the respective observed differential. According to the upper panel, growth differentials would have been very similar in the counterfactual scenario with symmetric structural parameters. This confirms our previous result that common shocks had little effect on growth differentials, suggesting that such shocks have a rather symmetric effect on economic activity in both regions.

Regarding inflation differentials, the lower panel shows that, even though they would have been qualitatively similar (i.e. peaks and troughs would have been largely coincident in time), quantitatively they would have been less volatile for most of the sample period, especially from 2002:Q1 onwards. In results not reported here but available upon request, we isolated the effect of each structural parameter by equalizing only one pair of parameters (the one in Spain to the one in the rest of EMU) at a 
time and computing counter-factual differentials. Our results indicated that the lower estimated degree of nominal rigidity in Spain $\left(\theta^{T}<F \theta^{T}, \theta^{N}<F \theta^{N}, \theta^{W}<F \theta^{W}\right.$ ) accounted for most of the difference between actual and counter-factual differentials in Fig. 14. As we saw in the previous section, shocks from the rest of the World played an important role in explaining inflation differentials. To the extent that this is due to faster price and wage adjustment in Spanish firms (in addition to other structural factors like a lower degree of openness or a stronger dependence on energy products), then raising the Spanish levels of nominal rigidities to EMU levels would have reduced fluctuations in inflation differentials. Interestingly, the substantially higher degree of wage indexation estimated for Spain has only played a minor role in inflation differentials. This suggests that wage indexation has small effects on equilibrium dynamics in our estimated model. ${ }^{15}$

\subsection{The effects of EMU membership}

We finally analyze to what extent inflation and growth differentials between Spain and the rest of EMU have been affected by Spain's membership of the European Monetary Union. Once again, our estimated DSGE model provides us with a helpful tool in order to address this question. Our approach here is to build a counter-factual model economy in which the economic structure and shocks in Spain and the rest of EMU would be exactly the same as in the estimated model, except for the fact that Spain retains its own currency (the peseta) and the ability to set its own nominal interest rates. In particular, we define the function $y\left(p, p^{*}, \mathrm{BdE} ; s, s^{*}\right)$, which is the set of differentials implied by certain parameter values $\left(p, p^{*}\right)$ and certain shocks $\left(s, s^{*}\right)$ in a version of BEMOD in which the Banco de España $(\mathrm{BdE})$ carries out its own monetary policy independently of the ECB. We then define

$$
y_{\text {diff }}^{\text {peseta }} \equiv y\left(P, P^{*}, \mathrm{BdE} ; S, S^{*}\right)-y^{*}\left(P, P^{*}, \mathrm{BdE} ; S, S^{*}\right),
$$

which is the set of differentials that would have been observed in the counter-factual scenario with independent monetary policy in Spain, given the parameters and historical shocks estimated in the baseline model. In particular, we assume that the coefficients in Spain's monetary policy rule would have been the same as those estimated for the ECB in Table 2, with the difference that the peseta interest rate responds to deviations of Spain's CPI inflation and output growth from their respective targets. By comparing $y_{\text {diff }}$ and $y_{\text {diff }}^{\text {peseta }}$, we can isolate how the fact that Spain belongs to EMU affects its macroeconomic behavior in relation to the rest of the currency area.

Figure 15 compares actual (solid line) and counter-factual differentials (dotted line) over the sample period, for both GDP growth and CPI inflation. The figure suggests that an independent monetary policy in Spain would have led to different growthinflation trade-offs. Most importantly, inflation differentials would have been lower

\footnotetext{
15 This result points in the same direction as the comparison between the prior and posterior distribution for the wage indexation parameters $\left(\psi^{W}, F \psi^{W}\right)$ in Fig. 4. The fact that both distributions are virtually on top of each other suggests that our data set, viewed through the lens of our DSGE model, contains little information regarding the wage indexation parameters.
} 

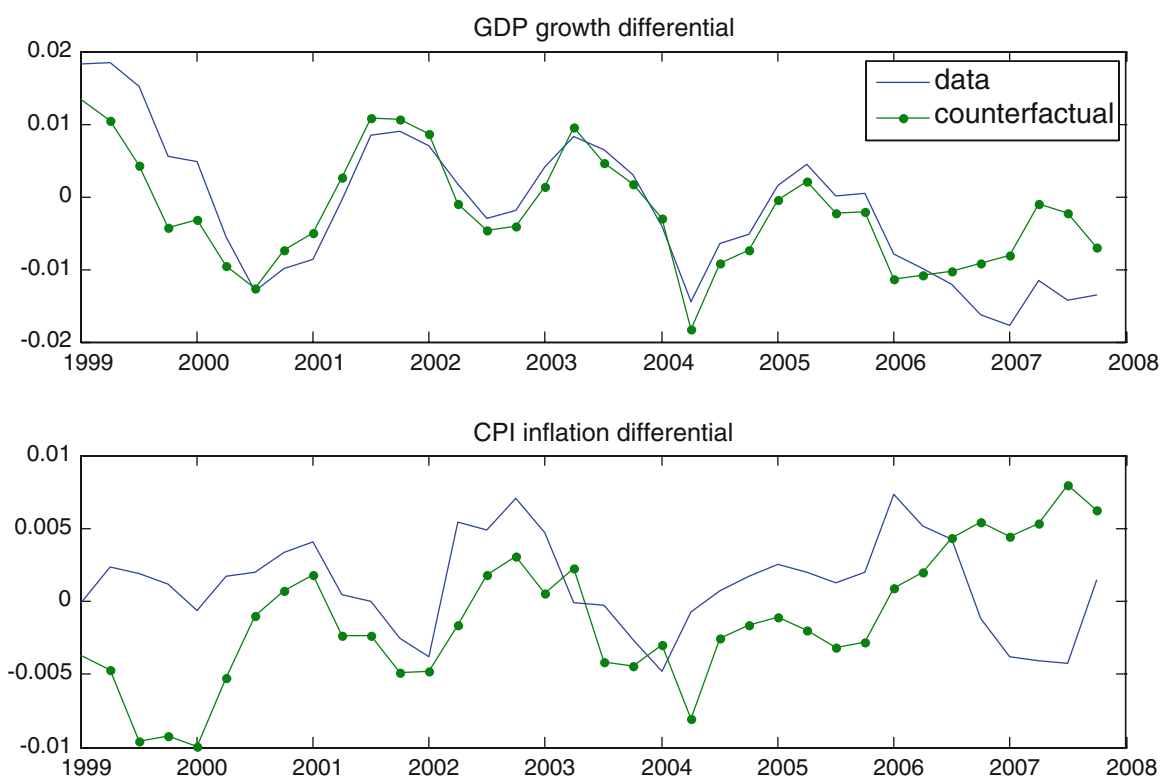

Fig. 15 The effect of Spain's EMU membership on differentials

all throughout the sample period, with the exception of the period 2006:Q3-2007:Q4. ${ }^{16}$ Interestingly, this cooling down of inflationary pressures would have produced only small reductions in relative growth, with the exception of 1999:Q1-2000:Q1 when such reductions would have been somewhat larger. A possible explanation for this finding is the following. In results not reported here but available upon request, we found that the counter-factual peseta nominal interest rate would have been above the observed euro nominal interest rate for most of the sample period (with differences of up to a hundred basis points in annual terms in certain periods). This would have led to a substantial appreciation of the peseta against the euro, which would have reduced the relative price of goods imported from EMU. Since the latter account for a non-negligible share of the Spanish CPI, it follows that the peseta appreciation would have helped contain inflationary pressures while causing only small reductions in GDP growth.

\section{Concluding remarks}

Since the launch of the Euro, the evolution of the Spanish economy has been remarkably different from that of the rest of the Euro Area. Both the rate of growth of GDP and the inflation rate have been systematically higher in Spain, and so has been the rate of

\footnotetext{
16 The actual levels of EMU growth and inflation barely change from the actual to the counter-factual scenario, due to the fact that Spain is small relative to the rest of EMU. Most of the difference between actual and counter-factual differentials is therefore due to a different behavior in Spanish growth and inflation.
} 
employment creation. These differentials stem partially from the ongoing process of convergence and from the integration of financial markets with strong repercussions in an economy that has resorted traditionally to foreign funds to finance a substantial gap between domestic savings and investment. These differences deserve a more careful scrutiny in the context of models combining high and low frequency fluctuations in the data.

Leaving aside these long term features there are shorter-term differences in the macroeconomic performance of Spain vis-à-vis the EMU. These differences can be explained by a combination of idiosyncratic shocks and the unequal speed of adjustment of prices and quantities arising from structural asymmetries between the two economies. BEMOD is designed to capture these features, thanks to the fact that the economic structure of Spain and the rest of EMU are modelled with the same degree of detail. Econometric estimation reveals however significant differences both in the series of historical shocks and in the structural parameters. The data is informative regarding the parameters governing price and wage dynamics as well as the stochastic processes of the shocks. The estimation reveals some moderate differences in these parameters across the two countries. In particular we find that nominal rigidities are somewhat smaller in Spain, especially for tradable goods prices, while wage indexation is much higher than in its EMU partners.

The model fit is good and the variance decomposition suggests that Spain-specific cost-push shocks play a very important role in accounting for the dynamics of inflation in Spain, but not in the rest of EMU where it is mainly driven by shocks from the rest of the World. The variance decomposition of Spanish value added is more balanced, with both Spain-specific demand and productivity shocks playing an important role. The historical contribution of shocks confirms these results for more specific episodes, uncovering the main reasons behind the fluctuations of the inflation and growth differentials.

The estimated model is used to perform three counterfactual exercises. First, we find that growth and inflation differentials between Spain and the rest of EMU would have been different during prolonged periods should the Spanish economy have experienced the same shocks as those estimated for its EMU partners. This is particularly true for the evolution during the early years of the Euro. Second, the structural specificities of the Spanish economy account for a non-negligible proportion of the volatility of differentials in CPI inflation. In particular, the lower degree of nominal price and wage rigidities estimated for the Spanish economy seems to have played an important role, by amplifying the effect of common shocks such as oil price shocks. Finally, EMU membership seems to have had a non-negligible effect on the volatility of growth and inflation differentials. In a version of BEMOD in which Spain is able to set its own monetary policy, we show that an independent monetary authority would have hypothetically pursued different output-inflation trade-offs for most of the sample period. In particular, during the 2002-2006 period the Spanish monetary authorities would have hypothetically cooled down inflationary pressures at the cost of slightly slower economic growth. It is important to remember that this is a counter-factual exercise which abstracts from the obvious benefits (credibility, etc.) of EMU membership for Spain, as well as from the equally obvious costs of actually implementing a change in the monetary regime. 
The specification and estimation of BEMOD is an ongoing project, since it is a model built for active use in the analysis of the various issues affecting the Spanish economy and the Eurozone over time. There are many issues in the research agenda regarding both the theoretical structure and the estimation process. Among them are the introduction of credit frictions. On the empirical side, further robustness checks regarding the set of observables are due and we also plan to extend the estimation to other parameters that have been calibrated in the current version. Finally, although the model contains a wide range of exogenous shocks, there is room for improvement on this front too.

Acknowledgments We would like to thank Angel Estrada, Juan Francisco Jimeno, Nooman Rebei and Alberto Urtasun for their help and very useful suggestions, and to Jesús Vázquez and participants of the conference "Estimation and Empirical Validation of Structural Dynamic Stochastic Models for the Spanish Economy" celebrated at Banco de España on 13 March 2009. Javier Andrés acknowledges financial support by CICYT grant ECO2008-04669. This paper represents the views of the authors and should not be reported as representing the views of the Banco de España or the Eurosystem.

Open Access This article is distributed under the terms of the Creative Commons Attribution Noncommercial License which permits any noncommercial use, distribution, and reproduction in any medium, provided the original author(s) and source are credited.

\section{References}

Adolfson M, Laséen S, Lindé J, Villani M (2005) Bayesian estimation of an open economy DSGE model with incomplete pass-through. Sveriges Riksbank, Working Paper 179

Álvarez LJ, Hernando I (2006) Price setting behaviour in Spain. Evidence from consumer price micro-data. Econ Modell 23:699-716

Álvarez LJ, Hurtado S, Sánchez I, Thomas C (2009) The impact of oil price changes on Spanish consumer price inflation. Banco de España Occasional Paper No. 09XX

Andrés J, Burriel P, Estrada A (2006) BEMOD: a DSGE model for the Spanish economy and the rest of the Euro Area. Banco de España Working Paper No. 0631

Aspachs-Bracons O, Rabanal P (2009) The drivers of housing cycles in Spain. La Caixa Working Paper Series 02/2009

Banco de España (2007) Adjustment of the Spanish economy: the real estate cycle and the functioning of the labour market, Chap 2 of the Banco de España Annual Report 2007

Burriel P, Fernández-Villaverde J, Rubio-Ramírez JF (2009) MEDEA: a DSGE model for the Spanish economy. FEDEA Working Paper 2009-17

Christoffel K, Coenen G, Warne A (2008) The New Area-Wide Model of the Euro Area: a micro-founded open-economy model for forecasting and policy analysis. ECB Working Paper Series No. 944, October 2008

Dhyne E, Álvarez LJ, Le Bihan H, Veronese G, Dias D, Hoffmann J, Jonker N, Lünnemann P, Rumler F, Vilmunen J (2006) Price changes in the Euro Area and the United States: some facts from individual consumer price data. J Econ Perspect 20(2):171-192

Druant M, Fabiani S, Kezdi G, Lamo A, Martins F, Sabbatini R (2008) How are firms' wages and prices linked: survey evidence in Europe, mimeo, Eurosystem

Du Caju P, Gautier E, Momferatou D, Ward-Warmedinger M (2008) Institutional features of wage bargaining in 22 EU countries, the US and Japan, forthcoming in ECB Working Paper Series

Erceg CJ, Henderson DW, Levin AT (2000) Optimal monetary policy with staggered wage and price contracts. J Monet Econ 46(2):281-313

Guerron-Quintana P (2008) What you match does matter: the effects of data on DSGE estimation. Mimeo López P, Estrada Á, Thomas C (2008) Una Primera Estimación del Impacto Económico de Una Reducción de las Cargas Administrativas en España. Boletín Económico del Banco de España, July-August 2008

Rabanal P (2009) Inflation differentials between Spain and the EMU: a DSGE perspective. J Money Credit Banking 41(6):1141-1166 
Schmitt-Grohe S, Uribe M (2003) Closing small open economy models. J Int Econ 61:163-185

Smets F, Wouters R (2003) An estimated dynamic stochastic general equilibrium model of the Euro Area. J Eur Econ Assoc 1(5):1123-1175

Tovar C (2008) DSGE models and central banks. BIS, Working Paper No. 258 